\title{
Women Empowerment and Skilled Attendance/Facility Delivery in a Rural Community of Western Kenya
}

\author{
Asweto, C. O. ${ }^{1,3}$, Ouma, J. O. ${ }^{3}$ Aluoch, J. R. ${ }^{1}$, Obonyo, C. O. ${ }^{2}$ \\ 1. School of Public Health and Community Development, Maseno University \\ 2. Kenya Medical Research Institute, Center for Global Health Research (KEMRI) Kisumu. \\ 3. Tropical Institute of Community Health and Development, Great Lakes University of Kisumu
}

\begin{abstract}
It is estimated that over 500,000 women die annually due to maternity complications, majority occur in the developing countries. In Kenya, maternal mortality ratio still remains high despite increased maternal health intervention efforts. Many developing countries have expanded their primary health facilities to improve access to maternal health services. However, disparity in use of health services is not very well understood. To determine relationship between women's empowerment and utilization of delivery care services, a survey of 403 mothers was conducted in Madiany division of Rarieda district, Kenya. About half the women had skilled delivery and health facility delivery. Predictors of skilled delivery and health facility delivery were education, autonomy, knowledge on pregnancy and delivery risks, occupation, parity, cost and travelling time. In order to move towards achieving MDG 5 we recommend empowering women by better education and income, and raising women's awareness on pregnancy danger signs by comprehensive health education.
\end{abstract}

Key words: Maternal Health Care Utilization, Delivery care services, Women empowerment, Maternal Mortality Ratio.

\section{Background}

Maternal mortality is still high worldwide, with $99 \%$ of these in developing countries ${ }^{23}$. In 2005, maternal mortality ratio was estimated at 900/100,000 live births for Sub-Saharan Africa with a lifetime risk of a maternal death of 1 in 22 (citation) compared to lifetime risk of 1 in 7300 developed countries ${ }^{24}$. In Kenya, KDHS 2008/9 estimated maternal mortality ratio (MMR) of 488/100,000 live births ${ }^{12}$. WHO estimated the life time risk of a maternal death in Kenya has been estimated at 1 in $39^{24}$.

Maternal health care has a major concern in demographic and other health outcomes and which also reflects the status of women in the society and empowerment level and also appalling the basic health care facilities in a particular region. ${ }^{19}$ Low social and economic status of girls and women limits their access to education, good nutrition, as well as money to pay for health care and family planning services. ${ }^{19}$ The extent of maternal mortality is an indicator of disparity and inequality in access to appropriate health care and nutrition services throughout a lifetime, and particularly during pregnancy and child birth and in a crucial factor contributing to high maternal mortality. ${ }^{14}$

The ability of women to make decisions that affect the circumstances of their own lives is an essential aspect of empowerment. Empowerment also leads in utilizing maternal health care because of the fact that if women are empowered in the sense of decision making and aware about the health care facilities then they will visit the health facilities more than that of those who are not aware about all those facilities.

In spite of the Government's effort to reach out to pregnant women in all parts of the country to provide all components of maternal health care free or with nominal charges, utilization of maternal health care remains low in the country ${ }^{16}$. According to KDHS 2008/9 only $44 \%$ of babies in Kenya were delivered by a health professional and in health facilities ${ }^{12}$ while in Nyanza province where study area falls, only $45.5 \%$ had skilled delivery attendance and $44.2 \%$ delivered at the health facility. In rural western Kenya ANC attendance has been high, but skilled assistance and facility delivery remained low $^{22}$. A significant proportion of women fail to seek delivery by trained health workers. The risks of unattended complications prevail and maternal deaths are likely under such situations.

Utilization of maternal health care depends not only the availability of services but also on different other factors such as distance of health care facility, perception of women and their families regarding the need for care, social restrictions on freedom to movement, the opportunity cost of accessing health care, and the interaction between the client and the provider of formal health care system ${ }^{10}$. As well as the status of women in society shows the utilization of maternal health care facilities. Education of mother is also an important reason that has performing the positive attitude on utilization of maternal health care ${ }^{25}$. On the other hand empowerment is a process of development of status of women in society and also influence in maternal health $\operatorname{care}^{14}$. Education, work participation, and the living standard also develops the decision making power of women as an integral part of empowerment. 
Empowerment is a process, by which women gain greater control over material and intellectual resources which will assist them to increase their self reliance and enhance them to assist independent rights and challenge the ideology of patriarchy and the gender based discrimination against women. This will also enable them to organize themselves to assert their autonomy to make decision and choices, and ultimately eliminate their own subordination in all the institutions ad structures of society ${ }^{14,25}$.

Maternal mortality is the focus of the Kenyan government policy on reproductive health operated by the national reproductive health strategy $2009-2015^{16}$. The first and important objective is the strengthening of maternal health services and increase access to skilled attendance at delivery. This would facilitate the country towards achieving MDG 5 targets which are to reduce by three quarters the maternal mortality and achieve universal access to reproductive health by 2015 .

The impact of women empowerment in utilization of maternal health care is the main aim of this paper. The proper utilization of maternal care depends on the knowledge and decision making power of women. Educated, employed and independent women are more concerned about their health mainly at the time of pregnancy. We enrolled women in Madiany Division of Rarieda district in western Kenya.

\section{Methodology}

\section{Materials and Methods}

A survey was conducted in Central Uyoma Location of Madiany division, Rarieda district, Siaya County, Kenya. Central Uyoma Location has three sub-locations namely, Kobong', Rachar and Masala, with a total of 35 villages. In 2009 census, the location had 3,145 households with a population of 13,830 people ${ }^{12}$. We estimated a minimum sample size of 387 to detect a minimum difference of $10 \%$ with $80 \%$ power and $\alpha=0.05$. Trained interviewers collected data by a standard questionnaire. Variables included socio-demographics characteristic, utilization of maternal health care, maternal knowledge on pregnancy and delivery danger signs, and health facility characteristics were collected.

The data was analyzed on SPSS for Windows 17.0 (SPSS Inc. Chicago. Illinois). Proportions were calculated in percentage while logistic regression was used to examine associated factors by estimating odds ratios with $95 \%$ confidence intervals.

We detailed the informed consent process to every participant and only those giving a written consent were enrolled in the study. The information gained both from the examination of the participants' records and from the questionnaire was kept confidential and used only for the purpose of this study. The questionnaire was carefully designed and took only a short span of time to administer so with little interference on the respondents' daily schedule. No other harm was anticipated from the study. Ethical approval was granted by the National Council for Science and Technology.

\section{Results}

Table 1 shows the respondents characteristics. Age ranged from 15 to 48 years, with a mean of 26.6 years. The 15-24 year olds were 45.1\%. The monthly family income ranged from Kshs. 500 to Kshs. 45,000, mean Kshs. 4,699.06/= per month. 129 (31.9\%) were housewives and $132(32.8 \%)$ engaged in microenterprises. Majority $(60.3 \%)$ had completed primary school and $80.1 \%$ had at least two children. Majority, $257(63.8 \%)$ of the respondents had no knowledge on danger signs of pregnancy and delivery, while $102(25.3 \%)$ of respondents had low knowledge and only $44(10.9 \%)$ respondents had high knowledge of danger signs of pregnancy and delivery.

Table 1: Respondents Characteristics

\begin{tabular}{|l|l|}
\hline Variable & Frequency $\mathbf{\%}$ \\
\hline Age (years) & $182(45.1)$ \\
\hline $15-24$ & $161(40.0)$ \\
\hline $25-34$ & $55(13.7)$ \\
\hline $45-44$ & $5(1.2)$ \\
\hline Monthly income (Kshs.) & $148(70.4)$ \\
\hline$<5000 /=$ & $62(29.6)$ \\
\hline$\geq 5000 /=$ & $120(29.7)$ \\
\hline Education & $243(60.3)$ \\
\hline None & $33(8.3)$ \\
\hline Primary & $7(1.7)$ \\
\hline Secondary & $44(10.9)$ \\
\hline Tertiary & $102(25.3)$ \\
\hline Knowledge & $257(63.8)$ \\
\hline High & \\
\hline Low & \\
\hline None & \\
\hline
\end{tabular}




\begin{tabular}{|l|l|}
\hline Employment \\
\hline Employed & $26(6.4)$ \\
\hline Farmer & $84(20.8)$ \\
\hline Businesswoman & $132(32.8)$ \\
\hline House wife & $129(31.9)$ \\
\hline Others (e.g. student) & $32(6.1)$ \\
\hline Parity & \\
\hline 1 & $80(19.9)$ \\
\hline $2-3$ & $169(41.9)$ \\
\hline $4-6$ & $131(32.4)$ \\
\hline $7+$ & $23(5.9)$ \\
\hline
\end{tabular}

\section{Utilization of Maternal health services}

Table 2 shows summaries of utilization of care services. About $50.4 \%$ respondents had their most recent delivery in a health facility. Skilled attendance at delivery was $52.6 \%$, TBA $33.3 \%$, while $6.5 \%$ had family assistance and $7.4 \%$ were not assisted. Of those who had skilled assistance, $96.7 \%$ of them delivered in the health facility. Majority $(70.4 \%)$ of TBA assisted delivery delivered in the TBA's house while $29.6 \%$ delivered in their own house. All those who were not assisted during delivery delivered in their own house.

Table 2: Attendance at delivery

\begin{tabular}{|l|l|l|l|l|l|}
\hline & Skilled & TBA & Family member & None & Total \\
\hline Place of delivery & $\mathrm{n}(\%)$ & $\mathrm{n}(\%)$ & $\mathrm{n}(\%)$ & $\mathrm{n}(\%)$ & $\mathrm{n}(\%)$ \\
\hline Health facility & $203(96.7)$ & $0(0 \%)$ & $0(0 \%)$ & $0(0 \%)$ & $\mathbf{2 0 3}(\mathbf{5 0 . 4 \%})$ \\
\hline TBA's house & $0(0 \%)$ & $94(70.4 \%)$ & $0(0 \%)$ & $0(0 \%)$ & $\mathbf{9 4}(\mathbf{2 3 . 3 \%})$ \\
\hline Own house & $6(2.3 \%)$ & $40(29.6 \%)$ & $23(76.9 \%)$ & $31(100 \%)$ & $\mathbf{1 0 0}(\mathbf{2 4 . 8 \%})$ \\
\hline Others & $3(1.0 \%)$ & $0(0 \%)$ & $3(8.3 \%)$ & $0(0 \%)$ & $\mathbf{6 ( 1 . 5 \% )}$ \\
\hline Total & $\mathbf{2 1 2}(\mathbf{5 2 . 6 \%})$ & $\mathbf{1 3 4}(\mathbf{3 3 . 3 \%})$ & $\mathbf{2 6}(\mathbf{6 . 5 \%})$ & $\mathbf{3 1}(\mathbf{7 . 4 \%})$ & $\mathbf{4 0 3}(\mathbf{1 0 0 \%})$ \\
\hline
\end{tabular}

\section{Maternal characteristics and care at delivery}

Table 3 shows association of maternal characteristics and health care utilization. Education increases the probability of a mother using the maternal health care services, mothers with primary education [OR=2.18 (1.38-3.43)] and secondary and above education [OR=7.62 (3.11-18.68)] more likely to deliver in health facility compared to those had no education. The same was also observed in delivery attended by skilled attendants, where mothers who had primary education were $[\mathrm{OR}=1.71(1.09-2.68)]$ and mothers with secondary and above education were $[\mathrm{OR}=5.79(2.46-13.66)]$ more likely to use services of skilled health care professionals during their delivery.

Knowledge of dangers signs of delivery and pregnancy is associated with place of delivery and delivery assisted by skilled attendant. Women with high knowledge were more likely to deliver in a health facility compared to women with low knowledge $[\mathrm{OR}=2.32(1.13-4.76)]$. Employment is associated with the use of health facility [OR=1.72 (1.15-2.57)] as well as skilled birth attendants $[\mathrm{OR}=1.76(1.18-2.63)]$. Parity is also associated with the place of delivery and skilled attendant assisted delivery. Mothers who primiparous were more likely to deliver in health facility $[\mathrm{OR}=1.79$ (1.06-2.93)], or being attended by skilled health care professional at birth [OR=1.76 (1.05-2.90)] compared to those who have more than one child.

Autonomy is associated with place of delivery and delivery assisted by skilled birth attendant. Women who self- reported they often make their own decisions and take the requisite action were more likely to deliver in a health facility $[\mathrm{OR}=2.07$ (1.01-3.86)] and get skilled health care professional assistance during delivery $[\mathrm{OR}=1.87(1.07$ 2.46)].

Table 3: Maternal characteristics

\begin{tabular}{|c|c|c|c|c|}
\hline & \multicolumn{2}{|c|}{ Health Facility Delivery } & \multicolumn{2}{|c|}{ Skilled Birth Attendant assistance } \\
\hline Variable & Freq $(\%)$ & OR $(95 \% \mathrm{CI})$ & Freq $(\%)$ & OR $(95 \% \mathrm{CI})$ \\
\hline \multicolumn{5}{|l|}{ Age } \\
\hline$\leq 24$ years & $102(56.0)$ & $1.00(0.68-1.49)$ & $101(56.0)$ & $1.12(0.76-1.66)$ \\
\hline$>24$ years & $106(55.8)$ & 1 & $118(53.1)$ & 1 \\
\hline \multicolumn{5}{|l|}{ Education } \\
\hline No education & $41(38.9)$ & 1 & $48(41.6)$ & 1 \\
\hline Primary & $133(58.1)$ & $2.18(1.38-3.43)$ & $137(54.9)$ & $1.71(1.09-2.68)$ \\
\hline$\geq$ Secondary & $34(82.9)$ & $7.62(3.11-18.68)$ & $34(82.9)$ & $5.79(2.46-13.66)$ \\
\hline \multicolumn{5}{|l|}{ Knowledge } \\
\hline High & $23(51.1)$ & $2.32(1.13-4.76)$ & $23(51.1)$ & $2.32(1.13-4.76)$ \\
\hline Low & $32(31.1)$ & 1 & $32(31.1)$ & 1 \\
\hline \multicolumn{5}{|l|}{ Work status } \\
\hline Working & $148(61.2)$ & $1.72(1.15-2.57)$ & $145(60.0)$ & $1.76(1.18-2.63)$ \\
\hline Not working & $60(47.9)$ & 1 & $74(46.0)$ & 1 \\
\hline \multicolumn{5}{|l|}{ Parity } \\
\hline 1 Child & $53(66.7)$ & $1.79(1.06-2.93)$ & $52(65.4)$ & $1.76(1.05-2.90)$ \\
\hline$>1$ Child & $155(53.2)$ & 1 & $167(51.7)$ & 1 \\
\hline
\end{tabular}


Women Empowerment And Skilled Attendance/Facility Delivery In A Rural Community Of Western

\begin{tabular}{|l|l|l|l|l|}
\hline With Autonomy & $195(58.1)$ & $2.07(1.01-3.86)$ & $187(55.8)$ & $1.87(1.07-2.46)$ \\
\hline No-autonomy & $13(44.9)$ & 1 & $32(47.8)$ & 1 \\
\hline
\end{tabular}

Health facility characteristics and utilization of delivery care

Table 4 show that time taken to reach health facility had significant influence on utilization of delivery care, those taking less than one hour to reach health facility were [OR=2.40 (1.27-4.66)] more likely to deliver in health facility and [OR=2.01 (1.30-3.11)] more likely to be assisted by a skilled birth attendant. Cost of delivery is associated with place of delivery and delivery assisted by skilled birth attendant [OR=1.70 (1.15$2.53)]$ and assistance by a skilled birth attendant $[\mathrm{OR}=1.50(1.00-2.23)]$. Perception on quality of care was found to have no significant relationship with place of delivery [OR=0.74 (0.46-1.18)] or delivery assisted by skilled delivery attendant [OR=0.77 (0.14-1.23)].

Table 4: Health facility attributes

\begin{tabular}{|l|l|l|l|l|l|}
\hline & Health Facility Delivery & \multicolumn{3}{l|}{ Skilled Birth Attendant assistance } \\
\hline Variable & Freq $(\%)$ & OR $(95 \% \mathrm{CI})$ & \multicolumn{4}{l|}{ Freq $(\%)$} & OR (95\% CI) \\
\hline Travelling time & $159(66.8)$ & $2.40(1.27-4.66)$ & $153(63.5)$ & $2.01(1.30-3.11)$ \\
\hline$\leq 60$ minutes & $49(45.6)$ & 1 & $58(46.4)$ & 1 \\
\hline$>60$ minutes & $127(62.3)$ & $1.70(1.15-2.53)$ & $121(59.4)$ & $1.50(1.00-2.23)$ \\
\hline Cost of Delivery & $81(49.3)$ & 1 & $98(49.3)$ & 1 \\
\hline$\leq 500 /=$ & $161(57.0)$ & $0.74(0.46-1.18)$ & $158(55.9)$ & $0.77(0.14-1.23)$ \\
\hline$>500 /=$ & $47(64.3)$ & 1 & $61(62.2)$ & 1 \\
\hline Perceived quality of care &
\end{tabular}

\section{Discussion}

The study assessed factors that determine the Health facility delivery and skilled birth attendant of mothers in Madiany, a rural western community. The study revealed that more than half had health facility delivery and skilled birth attendant assistance. The finding of this study is comparable to findings in the KDHS 2008/9 which showed that $43 \%$ of births in Kenya, and $44.1 \%$ of births in Nyanza province are delivered in a health facility, while $47 \%$ of births in Nyanza province are assisted by skilled birth attendant ${ }^{12}$. Health facility and skilled assisted delivery in Madiany have increased due to the fact that the recently started community strategy is providing equitable access to promotive and preventive health interventions through community health extension workers (CHEWs) and community health workers (CHWs) and also this study considered women who gave birth three years prior to the survey, while KDHS considered women who gave birth five years prior to survey. Although births in medical facilities have increased over the years there is still a long way to go, to reach the second National Health Sector Strategic Plan of achieving 80 percent of institutional deliveries by the year $2010^{17}$.

This study demonstrates that knowledge on danger signs of pregnancy and delivery increases use of maternal health care services. Consequently, increasing awareness on the danger signs will improve maternal health outcome. Kenthongkham (2007) and Erlindawati et al. (2008) showed linkage between awareness and maternal health service utilization, especially among the uneducated. According to Anson (2004), appropriate knowledge is the first factor that affects attitude, intention, and behavior. Amooti-Kaguna and Nuwaha (2000) argues that knowledge relates to behavior, which may produce attitudinal change toward service utilization.

Maternal education is considered the most important factor in determining women's delivery care seeking behavior. ${ }^{1}$ The findings from this study as shown that maternal education have significant influence on use of delivery services. Women with higher education were more likely to utilize health delivery facility and skilled birth attendant services. Some studies show an influence of maternal education on utilization of maternal health care services. ${ }^{3-5}$ By contrast, Magadi et al.(2000) found no relationship between the education of women and service utilization using a multivariate analysis of data from women of different communities in Kenya. The authors discuss that there is variability, at the community level, that influences the frequency of antenatal care visit during pregnancy ${ }^{13}$ However, in this study education level of women seems to be directly enhancing the utilization of maternal health care services through upgrading their knowledge.

Employment can increase women's economic autonomy and reproductive health status. This may be because it raises their awareness and provides new ideas, behavior and opportunities through interaction with other people outside the home and community. ${ }^{19}$ In this particular study, employment of women had a positive influence on the utilization of maternal health care. Working women were significantly more likely to use of health facility as well as skilled birth attendants for deliveries. Magadi et al. (2000) reported that in Kenya women in paid employment were more likely to have greater knowledge about pregnancy and childbirth due to freedom of movement outside the homestead. They also tend to seek information on services available for pregnancy care during work. ${ }^{13}$ 
The influence of women's autonomy on the use of health care appears to be as important as other known determinants such as education. Women's autonomy can be conceptualized as their ability to determine events in their lives, even though men and other women may be opposed to their wishes. ${ }^{4}$ This study found that autonomous women were more likely to deliver at health facility and to be assisted by skilled birth attendant during delivery. In fact, autonomy was found to significantly influence utilization of maternal health care services. Bloom et al.(2001) found that dimensions of autonomy such as freedom of movement, decision making power and control over finances exert a strong influence over service use and service choice in a South Asian setting. ${ }^{4}$ In a North Indian City, women's autonomy, as measured by the extent of a women's freedom of movement, appears to be a major determinant of maternal health care utilization among the poor to middle income women. ${ }^{4}$ Therefore, women's autonomy is an important factor to consider in determining maternal health care use.

With respect to the effect of parity on the utilization of delivery care, the results appear to agree with most previous studies, which indicate that women are significantly more likely to use delivery care services for their first child than later children. ${ }^{2,6,15}$ One possible explanation for this is that women who are pregnant with their first child are usually more likely to have difficulties during labor and delivery than women of higher parity. This may result in low parity women being more motivated to deliver in medical facilities than those with higher parity. In another study it was found that women who have more than one child are less likely to be users of both antenatal and delivery care services for subsequent pregnancies. ${ }^{15}$ Furthermore, in some studies the number of children in a family has a significant negative effect on maternal health care ${ }^{5}$. The higher the parity, the lower the use of adequate health care as women with large family size may tend to think that pregnancy is normal. ${ }^{13}$

This study shows that average time taken to reach health facility had greater influence on delivery care. Women who take shorter time to reach a health facility were more likely to deliver in the health facility and to be assisted by skilled birth attendant compared to women who resided further away. A similar conclusion was reached by other study showing that long distances to a health facility caused reduction in accessibility to maternal health care services. ${ }^{13}$ In rural areas, a lack of access roads to villages poses a serious problem, indicating that alternative approaches should be developed to better protect women's health.

Even though formal fees may be low or nonexistent, the informal fees or other costs still pose significant barriers to women's use of services. In this study, cost of delivery was found to have direct bearing on the place of delivery and delivery assisted by a skilled birth attendant; the findings revealed that high delivery cost tend to prohibit women from delivering in a health facility and being assisted by a skilled birth attendant. In another study done in Kenya, it was noted that medicines and other supplies often account for additional cost of delivery care. ${ }^{21}$ There are studies which have shown that availability of a hospital does not have any significant effect on the odds of giving birth in a medical institution because of the cost of delivery. ${ }^{7,20}$ Thus high cost of delivery is a prohibitive factor in maternal health care utilization. Therefore, high cost of services leads to a low level of utilization of maternal health services and keep millions of women from having hospital-based deliveries or from seeking care even when complications arise.

When women are assured of quality during delivery, then most maternal deaths can be prevented. However, in this study women's perceived quality of care had no statistical significant to the utilization of maternal health care services. Contrary to this, a study in Namibia found that, perceived low quality of health services in the health facilities is correlated with increases maternal morbidity and mortality. ${ }^{18}$ According to Fotso et al.(2006) the influence of women's perceived quality of care is strong in the expected direction for women with a high perception, who are more likely to deliver in an appropriate health facility compared to their counterparts with middle or low perception.

\section{Conclusion}

This study demonstrated that utilization of maternal health services ( delivery services) during the period of three year preceding the survey were relatively poor in the study area, since only a half of mothers had skilled and health facility delivery. This is attributed by low levels of awareness on the danger signs of pregnancy and delivery, which is a hindrance to maternal health care utilization. The study also shows that the most important factors influencing the use of maternal health services in the study area are education, autonomy, occupation, parity, cost of delivery and distance to health facility. Empowering women by improving educational opportunity for them may have a large positive impact on improving utilization of delivery care services. Since this go a long way in increasing their participation in gainful employment which give them autonomy on matters pertaining to their reproductive health.

\section{Recommendations}

The results of this study also highlight the importance of taking into account women empowerment when designing interventions intended to raise the use delivery-care services and community education about 
pregnancy, child birth and postpartum, particularly, the danger signs of pregnancy, labor and delivery and the actions ensuing complication need to get particular attention.

\section{Limitations of the Study}

Despite the contribution of the study to the literature on maternal health care, this study has some limitations. First, it is a cross-sectional study in which temporal relations could not be assessed. Second, there could be recall bias since the women were asked for events within the last three years prior to the survey despite the fact that, the most recent births were considered. Third, the study has considered only delivery of last child; the situations for deliveries of other children are unknown.

\section{Acknowledgements}

The author would like to thank Maseno University for sponsoring the research work. Also like to thank all respondents for their willingness to participate in the study. Without whose consent this research work would not have come into existence.

\section{References}

[1] Addai, I. Determinants of use of maternal-child health services in rural Ghana. Journal Biosocial Sciences, 2000; 32(1): 1-15.

[2] Amooti-Kaguna, B. and Nuwaha. Factors influencing choice of delivery sites in Rakai district of Uganda, Social Science and Medicine, 2000; 50: 203-213.

[3] Anson, O. (2004). Utilization of maternal care in rural HeBei Province, the People's Republic of China: Individual and structural characteristics.

[4] Bloom, S. S., Wypij, D. and Gupta, M. D. Dimension of women autonomy and influence on maternal health care utilization in North India City, 2001

[5] Celik, Y. and Hotchkiss, D. R. The socioeconomic determinants of maternal health care utilization in Turkey. Social Science Medicine, 2000; 50(12): 1797-1806.

[6] Chakraborty, N., Islam, M. A., Chowdbury, R. I. W. and Akhter, H. H. Determinants of the use of maternal health services in rural Bangladesh. Health Promotion International, 2003; 18(4): 327-337.

[7] Das, N. P., Mishra, V. K. and Saha, P. K. Does Community Access Affect the Use of Health and Family Welfare Services in Rural India? Mumbai (No. 18). Hawaii: International Institute of Population Sciences; East-West Centre, Population and Health Studieso, 2001.

[8] Erlindawati, Chompikul, J. and Isaranurug, S. Factors related to the utilization of antenatal care services among women at Aceh Darussalam Province, Indonesia. Journal of Public Health Development, 2008; 6: 99-108.

[9] Fotso, J. C., Ochako, R. A. and Ezeh, A. Interplay between women's percieved quality of, and access to care and household wealth on the utilization of maternity services among the urban poor, 2006.

[10] IIPS. Internal Institute for Population sciences, Mumbai, 2000.

[11] Kenthongkham, K. Knowledge, Attitude and Antenatal Care Practices of Women at Ad Distict, Huaphane Province, Laos. Health Service System Management, 2007; 53:45-63.

[12] KNBS. Kenya Demorgraphic Health Survey 2008/2009, 2010.

[13] Magadi, M. A., Madise, N. J. and Rodrigues, R. N. Frequency and timing of antenatal care in Kenya: Explaining the variation between women of different communities. Social Science and Medicine, 2000; 51(4): 551-561.

[14] Malhotra, A., Schuler, Sidney Ruth and Boender, Carol. Measuring women's empowerment as a variable in International Development, paper prepared for world Bank, 2002.

[15] Mekonnen, Y. Patterns of maternity care services utilization in Southern Ethiopia:evidence from a community and family survey. Ethiopia Journal of Health Development, 2003; 17(1): 27-33.

[16] MOH. Health service availability and utilization, 2006. Retrieved 22 January, 2011. from http://www.health.go.ke.

[17] MOH Reversing the trends, the Second National Health Sector Strategic Plan of Kenya-NHSSP II - 2005-2010, August, 2005. Retrieved 12 May, 2012. from http://www.health.go.ke.

[18] Ngula, A. K. Women's perception on the under utilization of intrapartum care services in Okakarara district, Namibia., University of Cape Town, 2005.

[19] Sharma, S. K., Sawangdee Y. and Sirirassamee B. Access to health: women's status and utilization of maternal health services in Nepal. Journal of Biosocial Science, 2007; 39: 671-692.

[20] Sugathan, K. S., Mishra, V. and Retherford. R. D. Promoting Institutional Deliveries in Rural India: The Role of Antenatal- Care Services. Hawaii: International Institute of Population Sciences; East-West Centre, Population and Health Studies, 2001.

[21] Suneeta, S., Sarah, S., Emily, S., Marissa, P., Varunj, D. and Rachel, S. Formal and Informal Fees for Maternal Health Care in Five Countries: Policies, Practices, and Perspective. USAID, 2005.

[22] van Eijk, A. M., Bles, H. M., Odhiambo, F., Ayisi, J. G., Blockland, I. E., Rosen, D. H., Adazu, K., Slusker, L. and Lindblade, K. A. Use of antenatal services and delivery care among women in rural western Kenya. Reproductive Health, 2006; 3(2).

[23] WHO and UNICEF. Antenatal care in developing countries. Promises, achievements and missed opportunities, An analysis of trends, levels and differentials, 1990-2001. Geneva: World Health Organization, 2003.

[24] WHO, UNICEF, UNFPA and World-Bank. Maternal Mortality in 2005: Estimates developed by estimates developed by WHO, UNICEF, UNFPA, and the World Bank. Geneva: World Health Organization, 2007.

[25] Yesudian P. Princy. Impact of Women's Empowerment Autonomy \& Attitude on Maternal Health Care Utilization in India, 2004. 